\title{
Frontozygomatik bölgede dermoid kisti bulunan bir olgu nedeniyle insizyon tekniklerinin gözden geçirilmesi
}

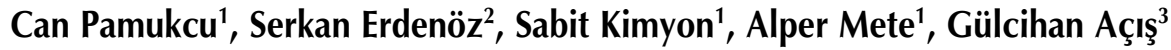

\begin{abstract}
ÖZET:
Frontozygomatik bölgede dermoid kisti bulunan bir olgu nedeniyle insizyon tekniklerinin gözden geçirilmesi

Dermoid kistler en yaygın görülen periorbital tümörlerdir. Total eksize edildikten sonra en önemli konu operasyon sonrası en iyi estetik sonucun alınmasıdır. Cerrahi sırasındaki insizyonun lokalizasyonu iyileşme sürecini etkilemektedir. Biz bu çalışmada dermoid kist eksizyonunda üst kapak kıvrımını kullandığımız bir olguyu sunarken insizyon tekniklerini sorguladık.

Anahtar kelimeler: Dermoid kist, frontozigomatik bölge, üst göz kapağı cilt kıvrımı

ABSTRACT:

Review of incision techniques in a case with frontozygomatic dermoid cyst Dermoid cysts are the most frequent periorbital tumors. The primary concern after total excision is an acceptable cosmetic result. Localization of incision during surgery effects the healing process and cosmetic result. In this report, we reviewed incision techniques while presenting a case in which we used upper skin crease incision for dermoid cyst excision.

Key words: Dermoid cyst, frontozygomatic region, upper eyelid skin crease
\end{abstract}

Ş.E.E.A.H. Tıp Bülteni 2013;47(1):45-48
'Sehitkamil Devlet Hastanesi, Göz Kliniği, Gaziantep-Türkiye

${ }^{2}$ Akyazi Devlet Hastanesi, Göz Kliniği,

Sakarya-Türkiye

${ }^{3}$ West Eye Hospital, Erbil, Irak

Yazışma Adresi / Address reprint requests to: Can Pamukçu, Şehitkamil Devlet Hastanesi, Göz Kliniği, Gaziantep-Türkiye

Telefon / Phone: +90-342-324-6767

E-posta / E-mail:

cpamukcu@gmail.com

Geliş tarihi / Date of receipt:

5 Ağustos 2012 / August 5, 2012

Kabul tarihi / Date of acceptance: 20 Kasım 2012 / November 20, 2012

\section{Giriş}

Dermoid kistler infant ve çocuklarda görülen en yaygın orbital tümörlerdir (1). Tüm orbital ve periorbital kitle lezyonlarının yaklaşık \%25'ini, 18 yaş altı bireylerde ise tüm orbital lezyonların yaklaşık $\% 50$ 'sini oluşturduğu bildirilmiştir $(2,3)$. Periorbital bölgede en yaygın olarak frontozygomatik sütür hattında lokalize olurlar $(1,4)$. Genelde soliter, mobil, düzgün sınırlı, ağrısız, orbital rime yakın oval kitlelerdir. En belirgin kemik değişikliği kemiğe basının sebep olduğu çukurlaşmadır. Olguların 1/3'ünde çevresindeki kemik duvarda tünel veya kanal vardır (5). Bilgisayarlı tomografi (BT) görüntülemede, bu lezyonlar çevre dokulardan iyi sınırlı bir şekilde ayrılır, yumuşak sınırları vardır ve sıvı seviyesi içerebilirler (6). Histolojik olarak benign olmakla beraber genişleme göstererek kemik erozyonu ve orbital yer değiştirme yapabilirler. Büyüme, sıklıkla kitle içeri- sindeki dermal ürünlerin yavaş birikimi ile olur. Spontan veya travmatik keratin içeriğinin sızıntısı, çevreleyen dokuda lokalize granülomatöz inflamatuar reaksiyon yapar. Asemptomatik olgularda uzun dönemde sızıntı ve inflamasyon yapmalarından dolayı cerrahi tedavi önerilmektedir $(7,8)$.

Bu makalede frontozygomatik sütür hattına yerleşik dermoid kisti olan olguda üst göz kapağı cilt kıvrımı insizyonu yolu ile kist eksizyonu anlatılırken insizyon teknikleri gözden geçirilmiştir.

\section{OLGU SUNUMU}

Doğuştan beri sol kaş dış tarafında kitle olan 9 yaşında erkek çocuk polikliniğimize başvurdu. Hastayla beraber kitlenin çapında da büyüme olduğu belirtildi. Kitle sol kaş dış kısımdaydı (Resim 1A). Kitlenin muayenesinde periosta yapışık ve mobil olduğu görüldü. BT ile değerlendirmesinde 18×12×10 mm 

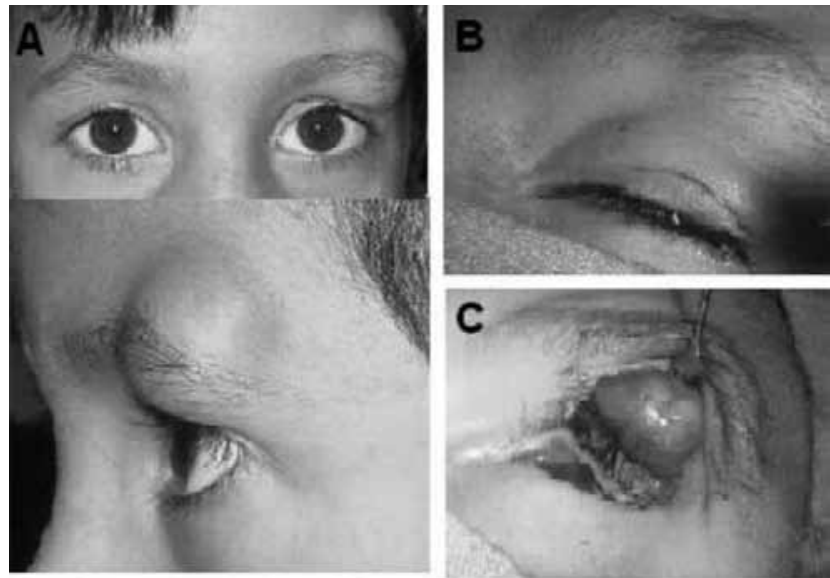

D

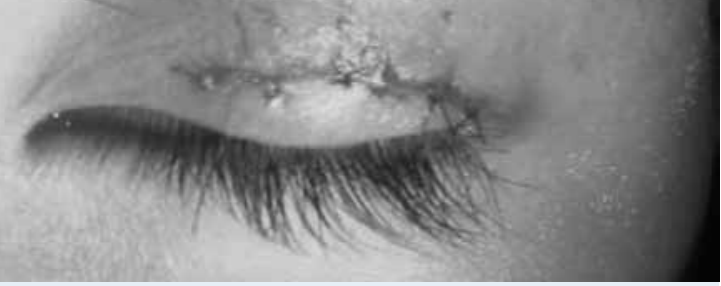

Resim 1: A- Sol kaş lateralinde dermoid kist bulunan hastanın görünümü, B- Sol üst kapağa lokal anestezi yapıldıktan sonra kapak cilt kıvrımı insizyonunu görülmekte, C- Üst kapak cilt kıvrımından kitleye ulaştıktan sonra kitlenin görünümü, D-Cildin 6,0 vicryl ile sütürasyonu sonrası sol kapağın görünümü.

çapında, periosta yapışık, santrali hipolusen olan kitlenin, orbital veya kranial uzantısı olmadığı görüldü (Resim 2). Hastaya cerrahi eksizyon önerildi.

Genel anestezi altında operasyon yapıldı. Üst göz kapağı kıvrımına ve lezyon çevresine \%1'lik lidokain, 1:100,000 epinefrin kombinasyonu enjekte edildi. Hastanın üst kapak kıvrımı işaretlenip yaklaşık 20 mm insizyon yapıldı (Resim 1B). Orbiküler kas açığa çıkarıldı. Cilt altından orbiküler kas üzerinden lezyona doğru yukarı ilerlendi. Kitleye yaklaşıldığında orbiküler kas geçildi ve kitleye ulaşıldı (Resim 1C). Kist tamamen çevre dokulardan diseke edildi ve altındaki periost ile birlikte eksize edildi. Cilt 6,0 vicryl ile sütüre edildi (Resim1D).
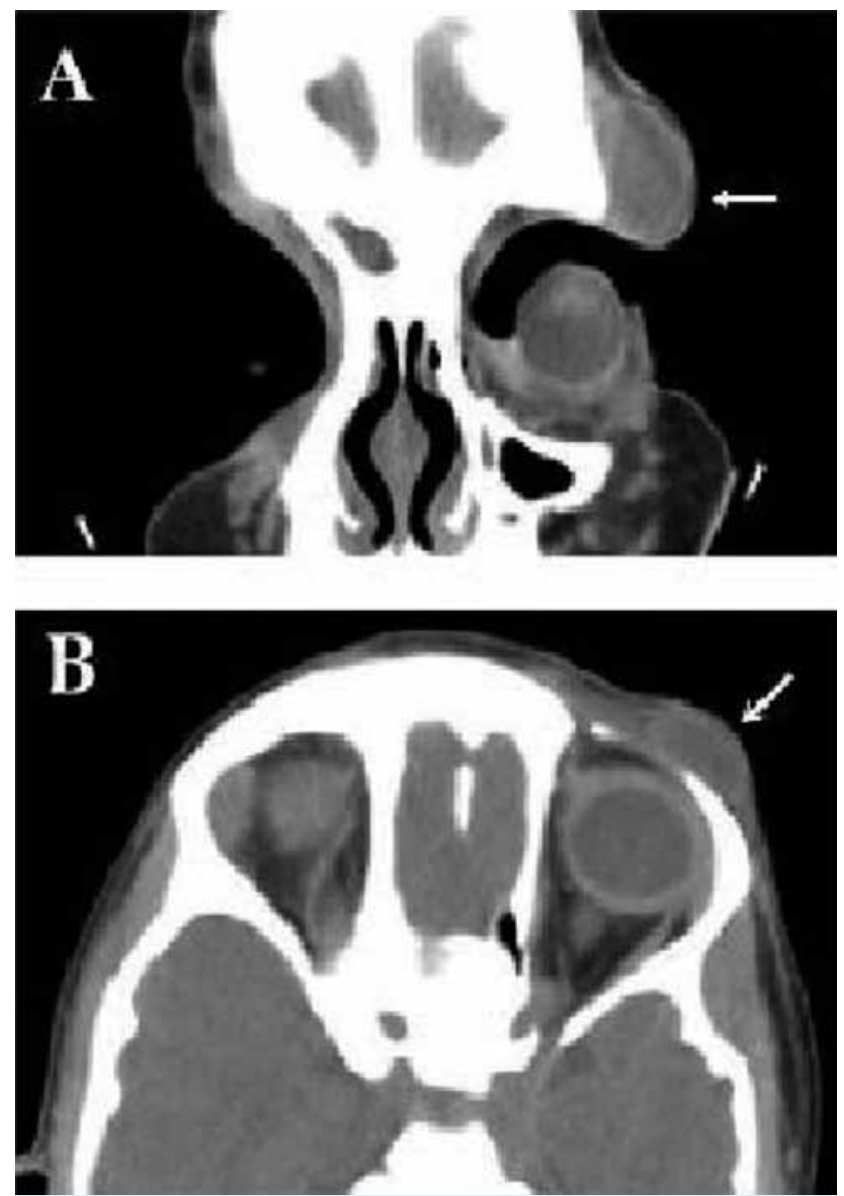

Resim 1: Kitlenin BT görünümü. A-Koronal orbital $B T$, B-Aksiyel orbital BT

\section{TARTIŞMA}

Dermoid kistler konjenital kalıntılardan gelişen benign kistik lezyonlardır. Keratinize skuamöz epitelle döşeli kistik yapı içinde saç, sebase ve ter bezleri gibi dermal ekler vardır. Rüptür olursa saç ve keratinden dolayı dev hücreli granülomatöz reaksiyon gözlenir $(9,10)$. Asemptomatik olgularda da uzun dönemde sızıntı ve inflamasyon olabileceğinden cerrahi tedavi önerilmektedir $(7,8)$. Dermoid kist eksizyonunda çeşitli lokalizasyonlarda insizyonlar kullanılabilinir. İnsizyon kitlenin hemen üstünden, süperior orbital rime paralel kaşın üst kısmından, alt kısmından, veya kaş içinden, orbito-nazal kıvrımdan (Lynch insizyonu), doğal üst göz kapağı kıvrımından veya endoskopik olarak ve lateral kantüs yolu ile yapılabilmektedir (11-19). Bazı yazarlar az skar bırakması nedeniyle üst kapak kıvrımını kullanmıştır (20-23).

Dermoid kistin eksizyonunda ideal olan cerrahi 
tekniğin, kitlenin bulunmasını kolaylaştırması, kısa sürede uygulanması, ve minimal skar bırakması istenir. Kitle üzerinde veya kaş çevresinde yapılan insizyonlarda sıklıkla iyi bir iyileşme görülürken bazen skar formasyonu veya insizyon hattı boyunca kaş kaybı olabilir. Lateral kantotomi yaklaşımı ise minimal skar ile iyileşme ve iyi bir görüş sağlar. Bu teknik orbital yerleşimli ve lateral periorbital alanda bulunan lezyonlar için uygundur. Fakat lateral kantotomi insizyonu birçok göz kapağı prosedüründe kullanılmakla birlikte daha çok bu bölgedeki orbital kistlerin cerrahisinde kullanılır (18). Bu nedenle frontozygomatik bölge lezyonları için ilk tercih edilecek insizyon değildir. Endoskopik yaklaşım saç çizgisi arkasından bir veya iki insizyon kullanılarak yapılır. Bu teknik potansiyel olarak fasial sinirin frontal dalının hasarı için risk oluşturur (24). Süperomedial tümörlere Lynch insizyonuyla yaklaşılabilir (13). Bu yaklaşım özellikle derin orbital yerleşimli orbital kitlelerin tedavisinde kullanılmaktadır. Bu yaklaşım troklea, süperior oblik tendon ve medial rektus kasında hasara neden olabilirken kesi yerinde belirgin skar gelişimine de yol açabilir $(16,19)$. Göz kapağının dikine insizyonu (The lid-splitting) tekniğini Smith tariflemiştir (18). Süperomedial orbita alan giriş insizyonudur. Belirgin skar gelişimi olabilir.

Leone ve Wolfley süperomedial orbital alana ulaşmak için doğal üst göz kapağı kıvrımı insizyonunu tariflediler ve bu çalışmada dermoid kist gibi orbitanın diğer alanlarındaki kitleler için de bu insizyo- nun kullanılabileceği bildirildi (19). Kaş lezyonlarına üst kapak kıvrımı insizyonu ile müdahale bazı yayınlarda tanımlanmıştır (20-23). Üst göz kapağı kıvrımı insizyonu lezyonun tam üzerine denk gelmemesi nedeniyle lezyona uzak bir yaklaşım gibi görünsede göz kapağının esneme özelliği sayesinde lezyonun tam üzerine çekilebilir ve insizyon hattı kaydırılmış olur. Ayrıca eksizyon için yeterli bir görüş sağlar. Bu yolla eksizyonda dikkatsiz diseksiyon levator aponevrozu ve lakrimal gland hasarı gibi potansiyel komplikasyonları barındırmasına rağmen dikkatli bir diseksiyonla bu komplikasyonlar görülmeyecektir. Hastamızda bu komplikasyonlardan herhangi biri görülmedi. Ayrıca diseksiyon yapılan alanın fazla olması nedeniyle post operatif ilk günlerde ödem ve ekimoz olabilmektedir (20).

Hastamızında postoperatif dönemde belirgin ödem gelişmedi. Göz kapağı cildi ince olması nedeniyle skar gelişimi minimal olacağından bu yöntemle belirgin skar gelişimi önlenecektir. Kaş insizyonlarında kaş bölgesinde cilt daha kalın olduğu için skarın daha fazla olması beklenmektedir.

Sonuç olarak kaş bölgesi dermoid kistlerin eksizyonunda üst kapak cilt insizyonu kullanımı basit ve güvenilir bir yöntemdir. Yeterli görüş imkânı sağlamakla birlikte avantajları yara iyileşmesinin iyi olma$\mathrm{sı}$, skar gelişiminin minimal olması ve yara yerinin kamufle edilebilmesidir. Bu nedenle kaş lateralindeki lezyonlarda üst kapak cildi kıvrımı insizyonu ile yaklaşımı önermekteyiz.

\section{KAYNAKLAR}

1. Nicholson DH, Green WR. Tumors of the eye, lids, and orbit im children, in: R. Harley(Ed.), Pediatric Ophthalmology, second ed., W.B. Saunders, Philadelphia, 1983.

2. Shields JA, Bakewell B,Augsburger JJ, Flanagan JC. Classification and incidence of space-occupying lesions of the orbit. A survey of 645 biopsies. Arch Ophthalmol 1984;102:1606-1611.

3. Shields JA, Augsburger JJ, Donoso LA. Orbital dermoid cyst of conjunctival origin. Am J Ophthalmol 1986;101:726.

4. Sherman RP, Rootman J, Lapointe JS. Orbital dermoids: clinical presentation and management. Br J Ophthalmol 1984;68:642652.

5. Chawda SJ, Moseley IF. Computed tomography of orbital dermoids: A 20- year review. Clinical Radiology 1999;54:821-825.

6. Darsaut TE, Lanzino G, Lopes MB, Newman S.An introductory overview of orbital tumors. Neurosurg Focus. 2001 May 15;10(5): E1

7. Lane CM, Ehrlich WW, Wright JE. Orbital dermoid cyst. Eye 1987; 1;504-511.

8. Sathananthan N, Moseley IF, Rose GE, et al. The frequency and clinical significance of bone involvement in outer canthus dermoid cysts. Br J Ophthalmol 1993;77:789-794.

9. Shields JA, Shields CL. Orbital cysts of childhood- classification, clinical features, and management. Survey of Ophtalmol 2004, Vol 49;3:281-297

10. Anlı A, Yağmur M, Yalaz M, Demircan N, Slem G. Çocukluk çağı oftalmik tümörler. Acta Oncologica 1995;28(1-2):12-15.

11. Grove AS, McCord CD Jd: Orbital disorders: Diagnosis and management, in McCord C Jr, Tanenbaum M (eds): Oculoplastic Surgery. New York, Raven Press, 1987, pp 223-256.

12. Henderson JW: Orbital Tumors. Philadelphia, WB Saunders Co, 1973, pp 86-123. 
13. Leone CR Jr: Surgical approachhes to the orbit.Ophthalmology 1979;86:930-941.

14. Wright JE: Surgical explaration of the orbit. in Stewart WB(ed): Ophthalmic Plastic and Reconstructive Surgery. San Francisco, American Academy of Ophthalmology, 1984, pp 309-315.

15. Howard GM: Cystic tumors in Jones IS, Jakobiec FA (eds): Diseases of the Orbit. New York, Harper \& Row Publishers Inc, 1979, pp 135-144.

16. Wolfley DE: The crease approach to the superomeial orbit. Ophthalmic Surg 1985;16:652-656.

17. Lin SD, Lee SS, Chang KP, Lin TM, Lu DK, Tsai CC. Endoscopic excision of benign tumors in the forehead and brow, Ann. Plast. Surg. 46(1)(2001) 1-4.

18. Smith B:The anterior surgical approach to orbital tumors. Ophthalmology 1966; 70:607-611.

19. Leone CR Jr. Surgical approach to orbital tumors, Ophthalmology 70 (1966) 607-611.
20. Kersten RC. The eyelid crease approach to superficial lateral dermoid cysts, J. Pediatr. Ophthalmol. Strabismus 25 (1988) 48-51.

21. Kronish JW, Dortzbach RK. Upper eyelid crease surgical approach to dermoid and epidermoid cysts in children. Arch Ophthalmol 1988; 106:1625-1627.

22. Garret WS, Ware, JL, Thorne FL. Dermoid cyst of the brow, a technique of excision, Plast. Reconstr. Surg. 39 (1) (1967) 104105.

23. Albert H. Park, Faizi Siddiqi. An approach to pediatric brow demoids: An upper eyelid crease incision. International Journal of Pediatric Otorhinolaryngology (2006) 70, 349-351.

24. Ruszkowski A, Caouette-Laberge L, Bortoluzzi P, Egerszegi $E P$. Superior eyelid incision: an alternative approach for frontozygomatic dermoid cyst excision, Ann. Plast. Surg. 44(2000) 591-595. 